\title{
Traffic management at the enterprises of the mineral industry
}

\author{
E.B. Mazakov \\ Candidate of Engineering Sciences, Associate Professor Head of the Department of Information systems \\ and computer engineering of Mining University, St. Petersburg, Russian Federation
}

\author{
K.V. Matrokhina \\ Graduate student, Mining University, St. Petersburg, Russian Federation \\ V.Y. Trofimets \\ Doctor of Science, professor at the Department of Information systems and computer engineering of Mining \\ University, St. Petersburg, Russian Federation
}

\begin{abstract}
The issues of traffic management in global computer networks are based on the apparatus of fuzzy logic are considered. As the fuzzy inference algorithm, the Mamdani algorithm was chosen. The rules of fuzzy inference are made, the functions of accessories of three types are constructed, the regularities of the logic of functioning of the proposed fuzzy controller are revealed. Traffic control modeling in the energy company's network was carried out on theory of queues and fuzzy logic. The main characteristics of the network are calculated with and without the use of the proposed fuzzy controller in the control loop, their comparative analysis is carried out.
\end{abstract}

Keywords: traffic control, bandwidth, fuzzy logic, Mamdani algorithm, membership functions, priority, delay, daily network load

\section{INTRODUCTION}

Every hour, over 100 thousand phone calls are made by companies in the mineral industry, more than 80 thousand emails are sent, more than 100 thousand different documents are generated in corporate business systems, and approximately $900 \mathrm{~TB}$ of information is stored in data centers.

At the same time, the situation is different for different units and divisions. So, for corporate functions and oil refining assets operating in megacities, there is always the opportunity to organize communication services almost instantly, since there are dozens of telecom operators. It is only necessary to make the right choice of price/quality/reliability ratio. The mining units, especially in the Far North, have a different situation there may not be any telecom operators at all. And then we have to create the necessary communication networks ourselves.

\section{LITERATURE REVIEW}

The construction of mechanisms, algorithms and protocols to implement the required quality of service for various applications and services of the communication network have long been the subjects of research by domestic and foreign scientists. The problem of improving the quality of network service and traffic management, in particular, was addressed in their writings by (Kucheryavyy 2014; Mazakov 2014; Katuntsov et al. 2017; Lidsky 2006; Stepanov 
2010; Melikov 2007; Brown Martin 2012; Tsvetkov 2011; Simakov 2016; Evseeva 2011; Katuntsov et al. 2018).

Recently, the number of works in which a fuzzy logic apparatus is used to control traffic has increased. So in work by (Potapchuk 2011), a routing method for a BSS network is described, based on a fuzzy logic apparatus. In contributions (Sorokin 2018), a technique is proposed for controlling the process of transmitting information traffic by regulating the load level of network device buffers. The technique includes the use of an adaptive fuzzy controller and neural networks.

For modeling fuzzy systems, as a rule, they use the MatLab computing environment in the Fuzzy Logic Toolbox package. Design issues, application of the decision-making method in fuzzy conditions are considered in the works of (Shtovba 2007; Leonenkova 2005; Bobyr 2018; Fedotova 2012).

The following is a new mechanism for managing traffic in global computer networks based on the Mamdani algorithm.

\section{METHODOLOGY}

Bursts of transmitted information volumes and imperfect traffic management methods lead to network congestion, resulting in buffer filling in queues and deteriorating service quality. Hence, there is a need to study traffic management processes and increase the efficiency of telecommunication systems in general.

To solve the traffic control problem in global computer networks, various algorithms are used, the most famous of which are TailDrop, PI, RED. These algorithms have shown their efficiency and acceptable efficiency, but, nevertheless, they are not free from disadvantages. For example, the TailDrop algorithm causes overload, and the RED algorithm changes the probability of a drop according to a linear law, but does not allow to effectively control the non-linear dynamics of traffic. The PI algorithm requires preliminary calculations in view of the use of machine learning.

To reduce the shortcomings of the mentioned algorithms, a traffic control mechanism in global computer networks based on a fuzzy logic apparatus was proposed.

Fuzzy logic arose as the most convenient way to build control systems and complex technological processes, and also found application in diagnostic and other expert systems. The fuzzy logic apparatus was proposed in 1965 by Lotfi A. Zadeh, a professor at the University of California, Berkeley. The applied aspects of using the fuzzy logic apparatus are reflected in the works of (Paklin 2014; Shtovba 2016; Motorygin Y.D. et al. 2016; Batkovskiy A.M. et al. 2017;Asadulaev 2017; Emelyanova 2013; P. Bauer 1997).

Consider the essence of the proposed approach to traffic management based on the Mamdani algorithm (see Figure 1).

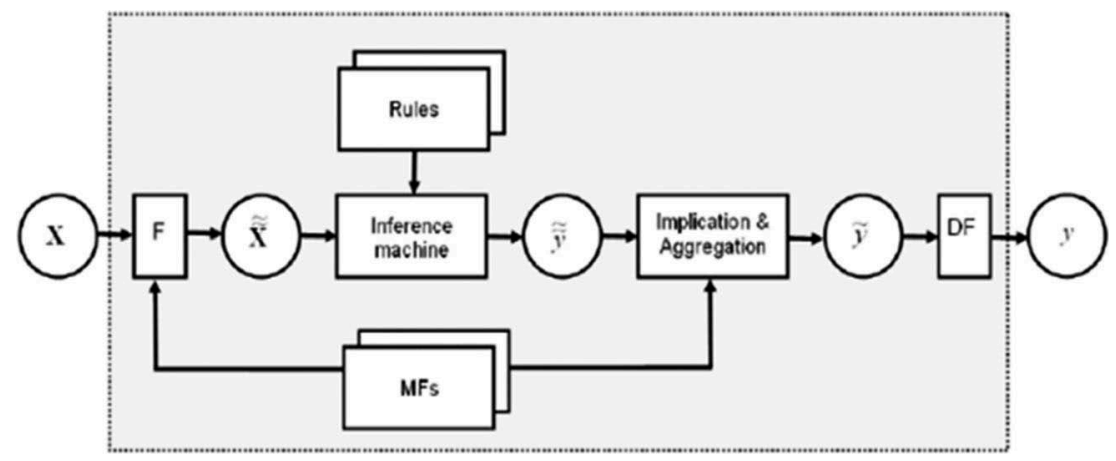

Figure 1. Mamdani algorithm structure. 
At the output of a fuzzy controller, built on the basis of the Mamdani algorithm, a clear value of the throughput is obtained, which can be found using defuzzification.

\section{RESULTS}

At the output of a fuzzy controller, built on the basis of the Mamdani algorithm, a clear value of the throughput is obtained, which can be found using defuzzification.

Next, the mechanism of the fuzzy logic apparatus is considered (see Figure 2).

As the object on which the proposed algorithm was tested, the energy company was selected whose offices are located geographically in different areas of the city. In the central region there are management units (VET, accounting, legal department, reception). In the northern region - operational personnel (electricians, installers), in the south of the city - a suburban branch. All units interact with each other, most often using the Internet to transmit information (see Figure 3).

The organization uses the services of an Internet provider, which, according to the agreement, provides the speed of $100 \mathrm{Mbps}$.

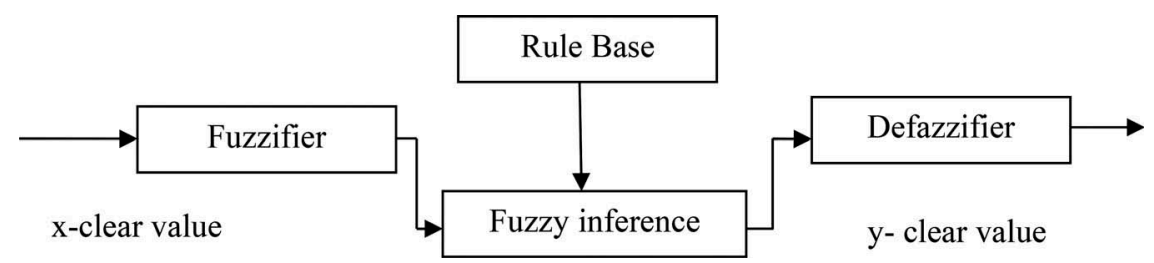

Figure 2. Fuzzy Inference System.

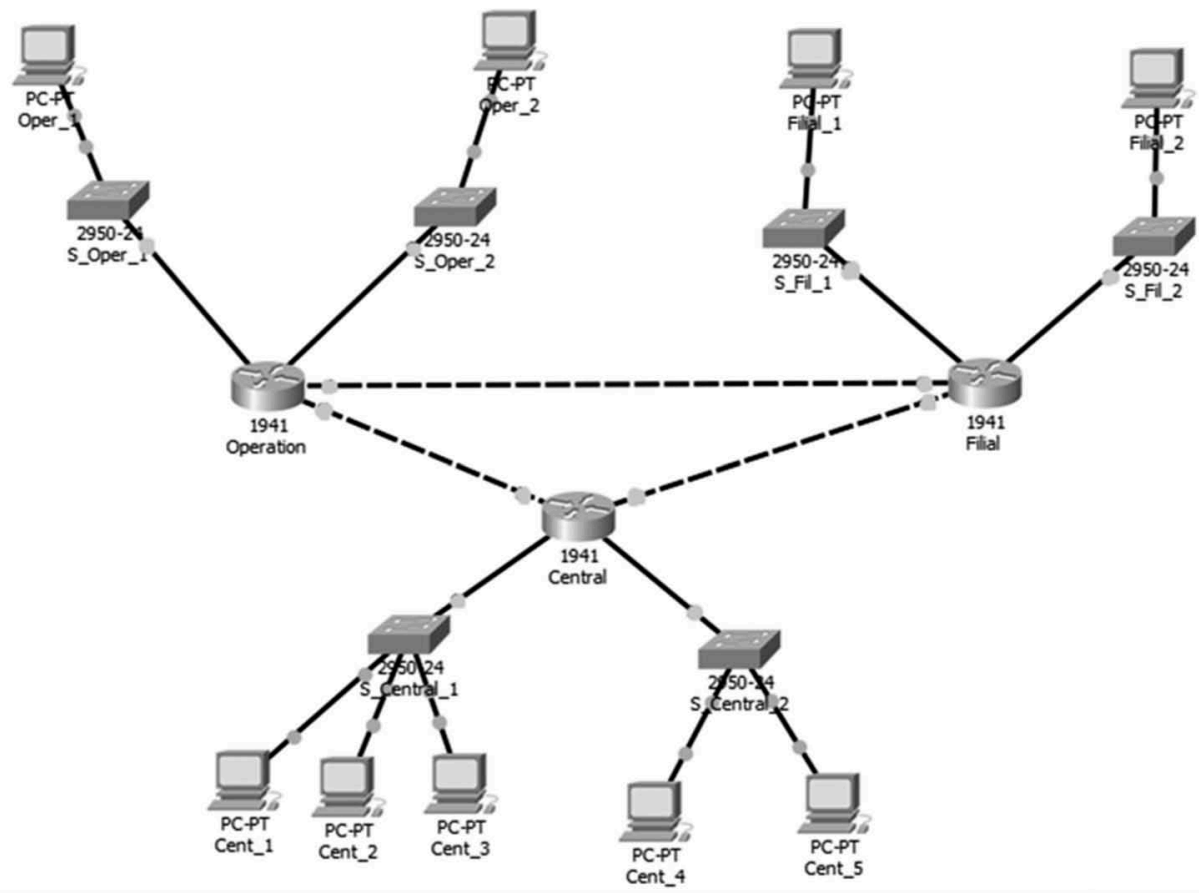

Figure 3. Organization network diagram. 
The most stringent bandwidth requirements are made by video, audio, voice, transactions. In view of the fact that the company in question uses these types of traffic quite often, Quality of Service (QoS) technology is used for this network. Thanks to this technology, you can distribute traffic by service category and priority. Guaranteed quality of service and better transmission conditions are provided for high-priority traffic, so $60 \%$ of the available bandwidth is allocated for transactions and voice, and about $5-10 \%$ for surfing.

1. There are some variables at the input (in operation, this is a delay, traffic priority and daily network load). Each variable has a numerical range of values. For priority, the values are from 0 to $100 \%$, for the delay from 0 to $200 \mathrm{~ms}$, for the daily network load from 0 to 24 hours. At the output, there is one variable, the network bandwidth, that is, the one that we control. It has values from 0 to $100 \mathrm{Mbps}$ (Figure 4).

Next, for each variable, linguistic variables are set to which intervals of values are assigned (see Figure 5-8)

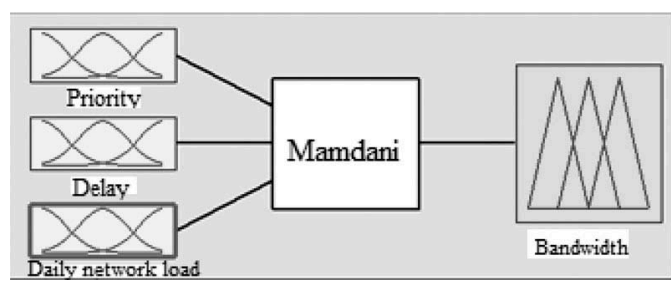

Figure 4. Fuzzy inference system.

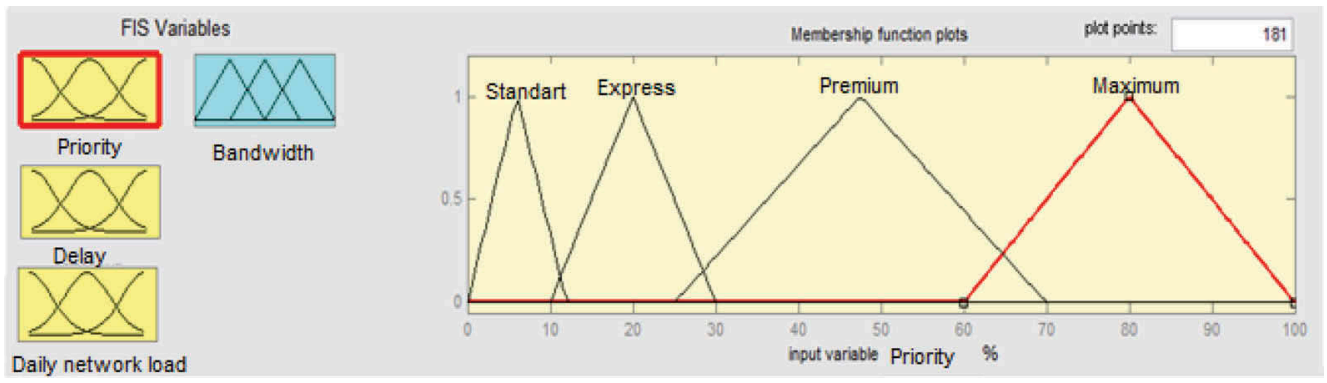

Figure 5. Membership functions for the input parameter "priority".

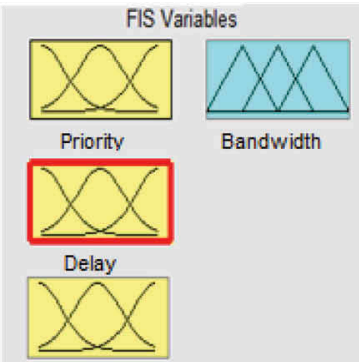

Daily network load

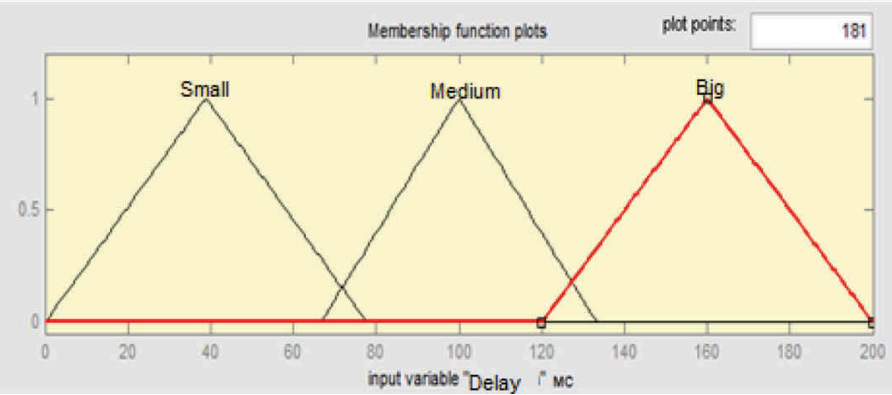

Figure 6. Membership Functions for the Delay Input Parameter. 


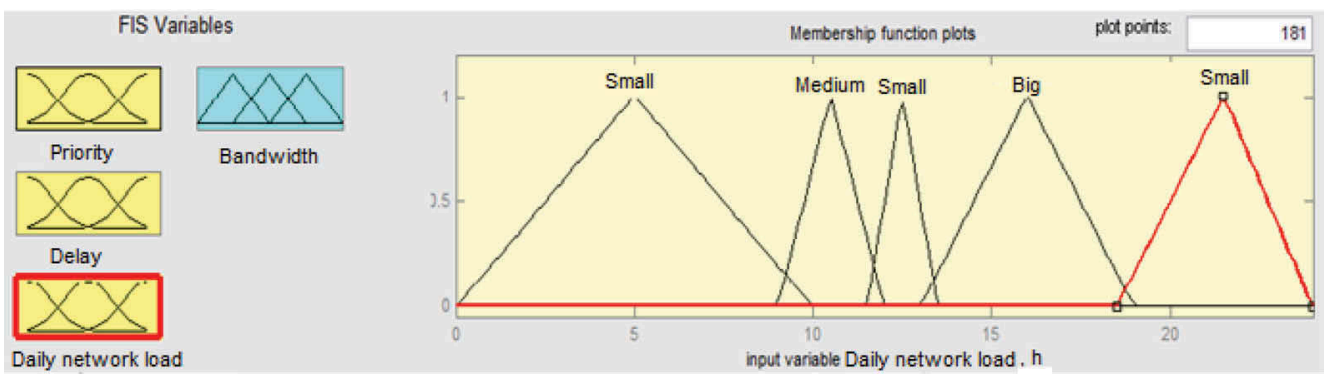

Figure 7. Membership functions for the input parameter "daily network load".

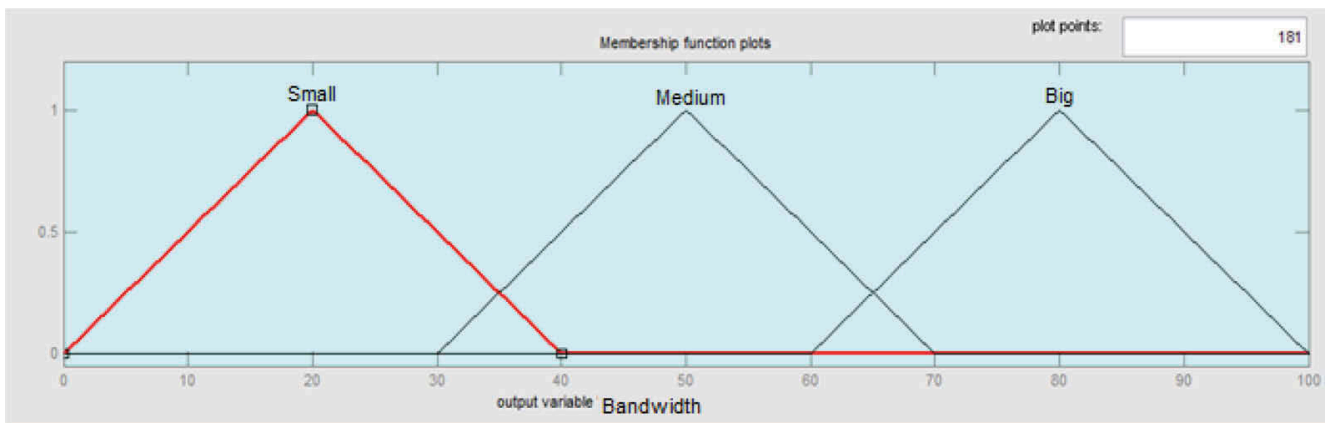

Figure 8. Membership functions for the output variable "user bandwidth".

Next, the base of rules for fuzzy inference is formed.

The logic of the fuzzy controller is as follows: for each variable, the throughput is calculated in accordance with the rule base.

The rule base includes $3 * 3 * 4=36$ rules, due to the fact that each variable takes on three or 4 different values. The full base is not given due to its size. It is important to note that all the rules were drawn up by competent experts in the amount of 20 people. Below are 10/36 rules from the fuzzy logic base:

1) if the priority is "maximum" and the delay is "small" and the daily network load is "small", then the throughput is "large";

2) if the priority is "premium" and the delay is "small" and the daily network load is "medium", then the throughput is "medium";

3 ) if the priority is "express" and the delay is "small" and the daily network load is "medium", then the throughput is "medium";

4) if the priority is "standard" and the delay is "medium" and the daily network load is "medium", then the throughput is "small";

$5)$ if the priority is "premium" and the delay is "medium" and the daily network load is "large", then the throughput is "medium";

6) if the priority is "express" and the delay is "large" and the daily network load is "large", then the throughput is "small";

7) if the priority is "premium" and the delay is "medium" and the daily network load is "small", then the throughput is "large";

8 ) if the priority is "standard" and the delay is "large" and the daily network load is "medium", then the throughput is "small";

9) if the priority is "maximum" and the delay is "large" and the daily network load is "average", then the throughput is "average";

$10)$ if the priority is "maximum" and the delay is "average" and the daily network load is "average", then the throughput is "small". 
4. In the end result, the output variable is reduced to clarity.

Below are the rules for linguistic variables with a triangular t-norm. (see Figure 9).

From fig. Figure 9 shows that with premium priority, average latency and low network load, the throughput is high $(80 \mathrm{Mbit} / \mathrm{s})$.

In addition, to obtain more reliable results, an analysis was performed using the symmetric Gaussian and trapezoidal membership functions.

Further, in Figure 10, you can see the visualization of fuzzy output Gaussian membership functions at given values of the input parameters

The trapezoidal membership functions are shown below visualization of fuzzy inference is presented (Figure 11).

Models for triangular, Gaussian and trapezoidal membership functions were considered. With the same input values of the variables (priority: 50\%; delay: $90 \mathrm{~ms}$; daily network load of 19.5 hours), there are different values of the output variable in all three cases, namely, for the triangular function: $80 \mathrm{Mbit} / \mathrm{s}$; for Gaussian: 77, $4 \mathrm{Mbps}$; for trapezoidal: $79.8 \mathrm{Mbps}$.

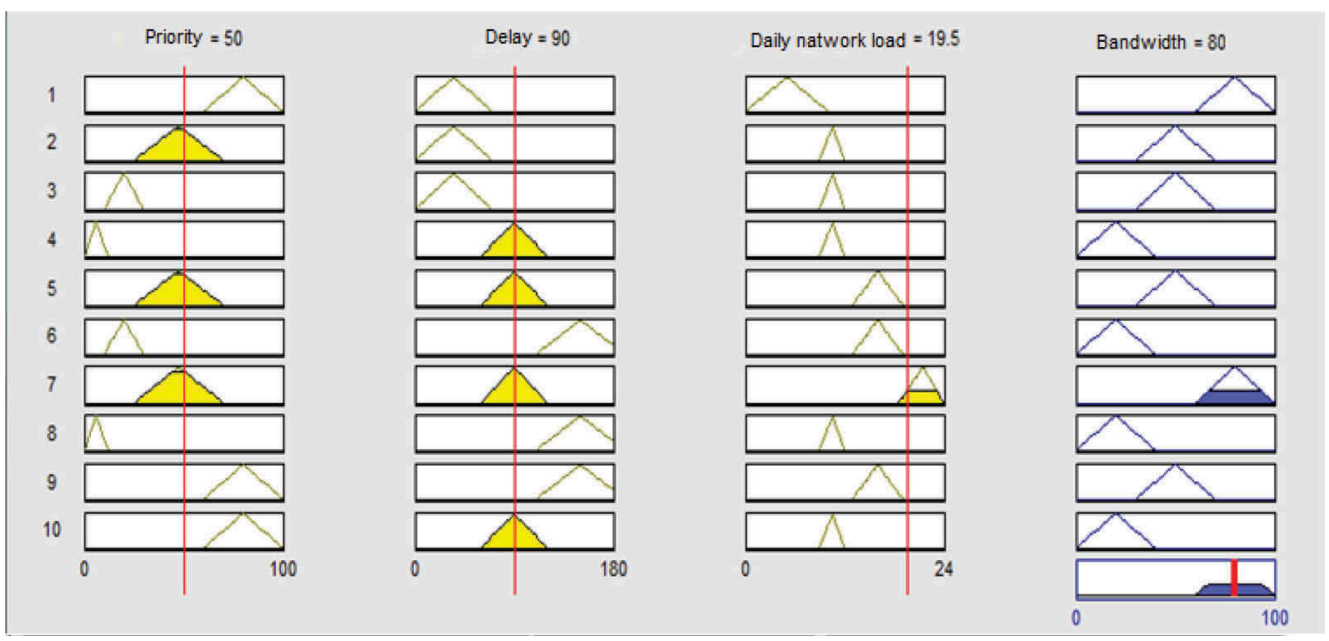

Figure 9. Visualization offuzzy output.
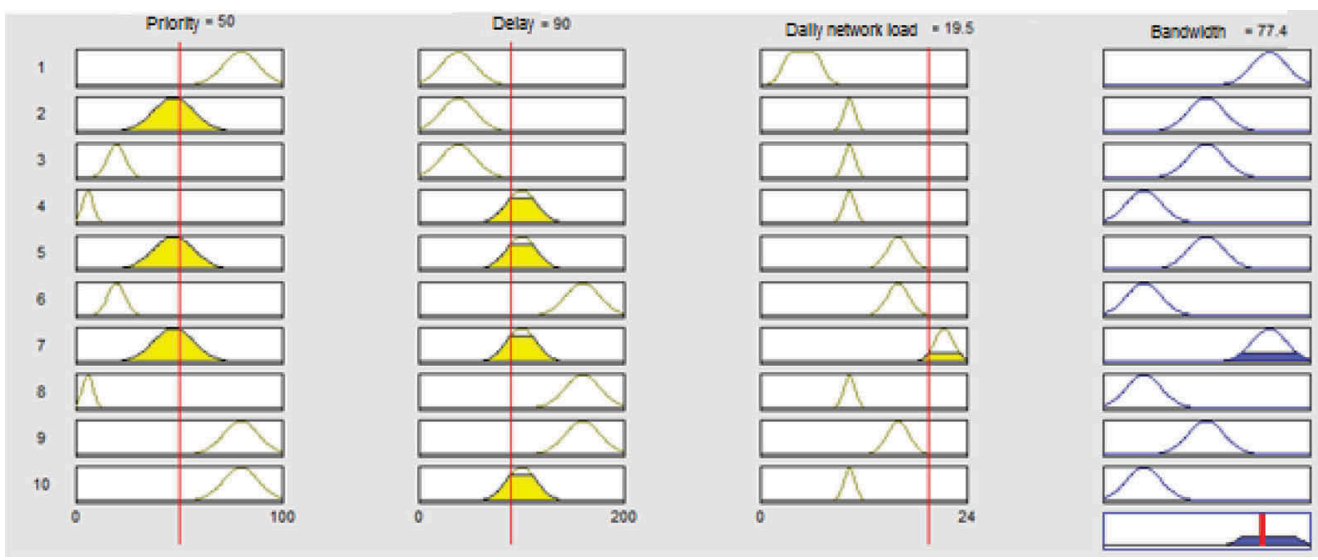

Figure 10. Visualization of fuzzy inference with Gaussian membership functions. 


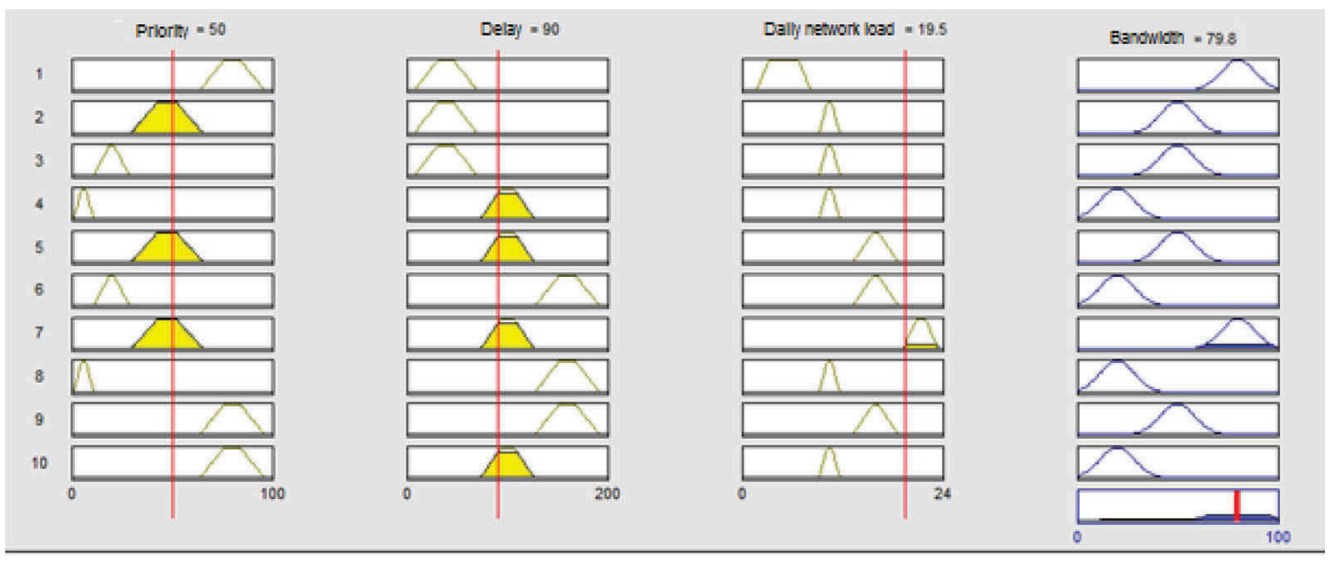

Figure 11. Visualization of fuzzy inference with Gaussian membership functions.

Further, for the problem under consideration, the main characteristics of the queuing system were calculated and graphs of the corresponding dependencies were constructed.

A queuing system having $\mathrm{n}=1$ service channel was considered. In this QS, a packet stream with an intensity of $\lambda=50 \mathrm{Mb} / \mathrm{s}, 80 \mathrm{Mb} / \mathrm{s}, 110 \mathrm{Mb} / \mathrm{s}, 140 \mathrm{Mb} / \mathrm{s}, 170 \mathrm{Mb} / \mathrm{s}$ was received at the input. The service intensity of each packet by the channel is $\mu-100 \mathrm{Mbit} / \mathrm{s}$ (router bandwidth). The maximum number of places in the queue is $\mathrm{m}=256$ (follows from the characteristics of the router). The graph of the system under consideration is presented in Figure 12.

Each state indicated in the circle means: S0 - the channel is free, there is no queue; S1 - there are no free channels, there is no queue; S2 - there are no free channels, in line 1; S3 - there are no free channels, in line 2; S257 - there are no free channels, there are 256 in the queue.

Based on the results of the calculation of the main characteristics, graphs were built of the dependence of each characteristic on the intensity of packet arrival. Below are some graphs of functions with and without fuzzy logic (blue indicates the function without using the fuzzy logic apparatus, red means using the apparatus, see Figures 13-15).

As a result of the simulation, the following results were obtained: on the graphs (Figure 13-15), you can notice that with the use of a fuzzy logic apparatus, the probability of failures and queuing are reduced, and the absolute throughput increases.

\section{CONCLUSION}

Thus, in the framework of the study, traffic management issues in global computer networks based on the fuzzy logic apparatus were considered. As the fuzzy inference algorithm, the Mamdani algorithm was chosen. The rules of fuzzy inference are made, the functions of accessories of three types are constructed, the regularities of the logic of functioning of the proposed fuzzy controller are revealed. It has been established that it is advisable to use triangular membership functions, since their use allows you to provide the user with the highest throughput.

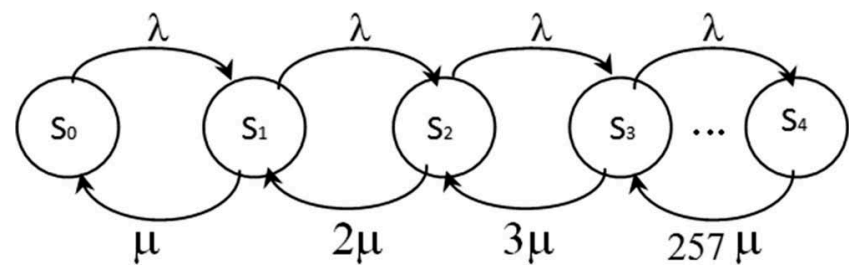

Figure 12. Count of a given queuing system. 


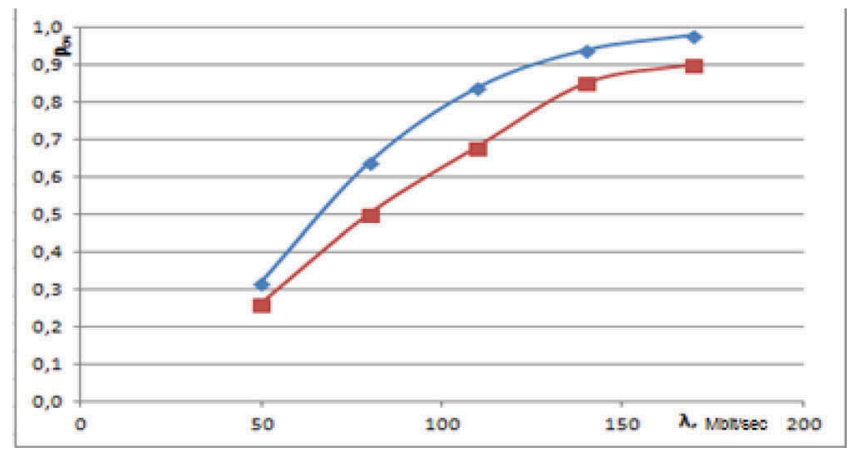

Figure 13. Schedule of queuing versus bandwidth.

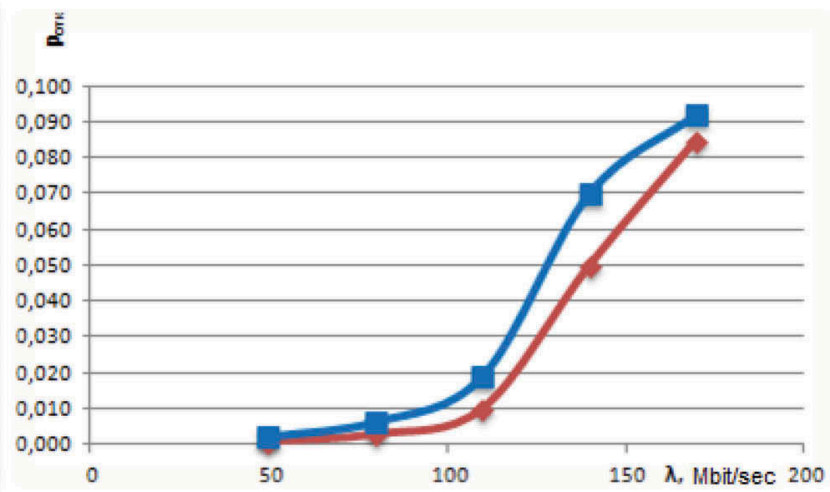

Figure 14. The graph of the probability of failure from bandwidth.

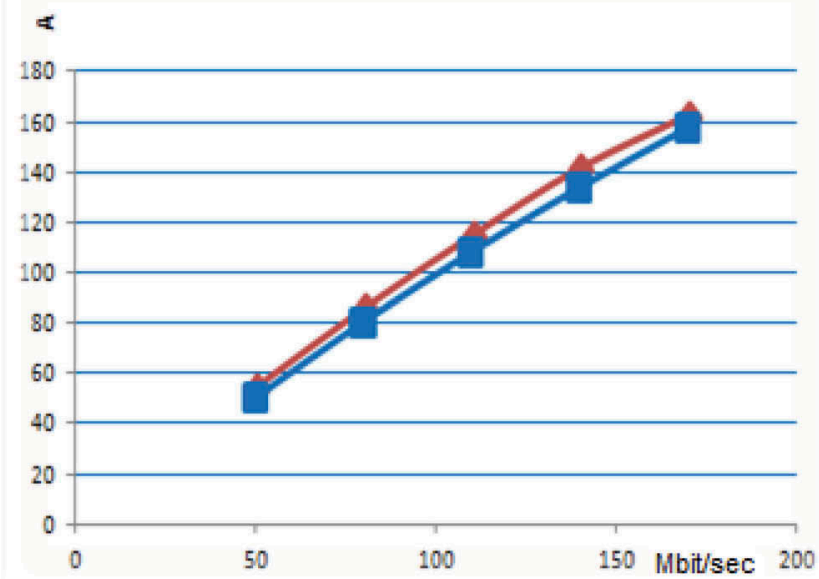

Figure 15. Graph of absolute throughput versus service intensity. 


\section{REFERENCES}

Asadulaev R.G., 2017.Fuzzy logic and neural networks, Belgorod, BelSU: 309

Batkovskiy A.M., Semenova E.G, Trofimets E.N., Trofimets V.Ya., Fomina A.V. 2017. Modified method for sensitivity analysis of investment projects efficiency criteria. Journal of Applied Economic Sciences, Romania: European Research Centre of Managerial Studies in Business Administration. Volume XII, Issue 4(50). Fall 2017: p. 1116-1131

Bauer P., 1997. Introduction to fuzzy logic and fuzzy control system Internet journal: 14.

Brown Martin, 2012. How to on traffic management using NTV, online magazine: 200.

Bobyr M.V., 2018. Designing neural and fuzzy models in the field of computer technology and control systems teaching aid, Moscow "Agramak-Media": 110.

Emelyanov S.G., 2013. Adaptive fuzzy-logical control systems, Moscow:193

Evseeva O.Yu., 2011. Methodology of experimental studies of network traffic control methods, Electronic Scientific Specialized Edition - Journal of Telecommunication Problems: 89-104.

Fedotov V.Kh., 2012. Intelligent Information Systems. Workshop ed. Chuvash State University:78.

Katuntsov E.V., Kosarev O.V., Makhovikov A.B., Tcvetkov P.S. 2018. Digital transformation in oil and gas ex-traction. Innovation-Based Development of the Mineral Resources Sector: Challenges and Prospects - 11th conference of the Russian-German Raw Materials, 2018, Potsdam, Germany. - CRC Press/Balkema, 2019: p.531-538

Katuntsov, E.V., Kultan, Y., \& Makhovikov, A.B. 2017. Application of electronic learning tools for training of specialists in the field of information technologies for enterprises of mineral resources sector. Journal of Mining Institute,226:p.503-508.

Khizhnyakova Yu.N. 2013. Algorithms of fuzzy, neural and fuzzy neuronal control in real time, Publishing house of the Perm National Research Polytechnic University.

Kucheryavy E.A. 2004. Traffic management and quality of service on the Internet, St. Petersburg. Science and Technology:336.

Leonenkov A.V. 2005, Fuzzy modeling in MATLAB and Fuzzy TECH ed. "BHV-Petersburg":736.

Lidsky E.A., 2006.Traffic problems in communication networks, Textbook, Yekaterinburg, UGTTU-UPI GOU VP:202.

Mazakov E.B.,2014 Representation and processing of knowledge in information automated systems of intelligent field, Journal of Mining Institute,208:p.256-262.

Melikov A.Z., 2007 Teletraffic: models, methods, optimization, Internet Journal, p.256.

Motorygin Y.D., Artamonov V.S., Maximov A.V., Trofimets E.N., Trofimets V.Ya.2016. Management of the Formation of Rating Preferences of Economic Entities upon Collective Choice. International Journal of Economics and Financial Issues, 2016, 6(4):p. 1956-1964

Paklin N. Fuzzy logic-mathematical foundation, Internet journal:12.

Potapchuk I.A., 2016. Routing method in a wireless self-organizing network based on fuzzy logic apparatus, Technique and electronics of high voltage: 82-88.

Shtovba S.D. 2007. Designing fuzzy systems using MATLAB, Hotline-Telecom:288.

Shtovba S.D. Introduction to the theory of fuzzy sets and fuzzy logic, Internet journal: 209.

Simakov D.V. 2016. Traffic control in a network with high dynamics of network route metrics Internet journal "Science of Science: 1-13.

Sorokin A.A. 2018. Adaptive fuzzy management of the State Polytechnic University. Computer science. Telecommunications. Management: $36-48$

Stepanov S.N. 2010. Fundamentals of teletraffic of multiservice networks, Moscow, Eco-Trends:392

Tsvetkov V.Yu. 2011. Billing-management of multiservice network traffic, methodological manual, Minsk, BSUIR: 50. 